\title{
Relationships between calpains and glutamate- or kainate-induced apoptosis in Xenopus laevis tadpoles
}

\author{
Claire Brun, Elara Moudilou, Caroline Bouchot, Lucie Abrouk-Vérot, \\ Jean-Marie Exbrayat
}

Université de Lyon, UMRS 449, Laboratoire de Biologie générale, Université Catholique de Lyon, Laboratoire de Reproduction et Développement Comparé, EPHE, Lyon, France

\begin{abstract}
Cell glutamate-damage induced by overstimulation of ionotropic receptors is initiated by modification of the intracellular $\mathrm{Ca}^{2+}$ homeostasis and the concomitant activation of $\mathrm{Ca}^{2+}$-dependent cysteine proteases, the calpain and caspase families. The resultant cleavage of target molecules mediates a critical function in the execution of the cell death. In this work, we investigated relationships between the activity of calpain and glutamate- or kainate-induced apoptosis in several organs of Xenopus laevis tadpole. Animals (stage 48) were incubated for 3 hours with glutamate $(30-120 \mathrm{mM})$ or kainate $(0.015-0.75 \mathrm{mM})$ and the rise of both apoptosis and calpain was observed in several organs. Our results indicated that glutamate $(120 \mathrm{mM})$ or kainate $(0.15 \mathrm{mM})$ exposure induced cell death with apoptotic features. The toxic effects of drugs into the organs were variable. Apoptosis was probably not the only form of cell death and option of necrosis or apoptosis was depending on the stimulation degree of the receptor, i.e. the receptor type, intensity and time course of molecule exposure. The increase of ubiquitous calpain was not correlated with the peak of apoptosis, suggesting the role of calpain in cell death was complex: calpain and caspase pathways were tightly interrelated in the glutamate- or kainate-induced cell death and the contribution of calpain to another type of death than apoptosis was perhaps preferred. (Folia Histochemica et Cytobiologica 2013, Vol. 51, No. 4, $x-x$ )
\end{abstract}

Key words: calpain; apoptosis; ecotoxicity; glutamate receptors; calcium; Xenopus laevis

\section{Introduction}

Glutamate (Glu) is an essential occurring amino acid, involved in intermediary metabolism and non-neuronal functions, with a major role as excitatory neurotransmitter in the brain [1]. The varied functions of Glu are dependent on specific interactions with ionotropic and metabotropic glutamate receptors (iGluR and $\mathrm{mGluR}$, respectively). The mGluRs are G-protein coupled receptors and fall into three categories according to their pharmacological sensitivities $[2,3]$. The iGluRs possess an intrinsic cationic channel and are divided into three pharmacological types based on their typical agonists: the N-methyl-D-aspartate

Correspondence address: J.-M. Exbrayat, UMRS 449, Laboratoire de Biologie générale, Université Catholique de Lyon, Laboratoire de Reproduction et Développement Comparé, E.P.H.E., 25 rue du Plat, 69288 Lyon Cedex 02, France; e-mail: jmexbrayat@univ-catholyon.fr
(NMDA), the $\alpha$-amino-3-hydroxy-5-methylisoxazole proprionic acid (AMPA) and the kainate (KA) receptors [4]. The non-NMDA receptors (non-NMDAR) control a non-selective cationic channel permeable to $\mathrm{Na}^{+}$and $\mathrm{K}^{+}$, whereas NMDAR are more permeable to $\mathrm{Ca}^{2+}$ ions than AMPA or KA receptors [5]. Glutamate receptors (GluR) are expressed mainly in the central nervous system, but their distribution has been mentioned in peripheral tissues [6]. The toxic effect of Glu was essentially described in the brain, as "glutamate excitoxicity" characterised by neuronal dysfunction and degeneration [7, 8]. Indeed, an excessive concentration of Glu could result in a constant stimulation of GluR and a deregulation of intracellular calcium homeostasis, mainly through NMDAR activation $[9,10]$. Afterwards, the high concentration of $\mathrm{Ca}^{2+}$ lead up to the activation of several enzymes pathways and signalling cascades, which trigger necrotic or apoptotic cellular death [11]. Calpain family occurs among the downstream targets of glutamatergic transmission [12-14]. 
Calpains are a large conserved family of cysteine proteases regulated by calcium, which partly cleave many different substrates (cytoskeletal proteins, phosphatases and kinases, receptors and ion channels), modulating the protein activities $[15,16]$. Calpains were demonstrated to be implicated in a wide range of cellular processes - proliferation, cell migration, cell differentiation, or programmed cell death (PCD) - and thus are probably necessary in all the stages of cell life [17]. Calpain 1 and calpain 2 (also known as $\mu$-and $\mathrm{m}$-calpains) are the best characterised conventional calpains. These ubiquitous proteases consist of an 80-kDa catalytic subunit (with approximately $60 \%$ sequence homology between them) and a 30-kDa regulatory subunit (identical for both enzymes). In vitro, calpain 1 and calpain 2 are activated by micromolar or millimolar concentrations of $\mathrm{Ca}^{2+}$ respectively. Calpains exist as inactive proenzymes in the cytosol. An increase in the intracellular $\mathrm{Ca}^{2+}$ concentration triggered their activation and the processes were strictly calcium dependent [15, 18-21]. Uncontrolled calpain-mediated proteolysis of substrates was prevented by calpastatin, the specific endogenous intracellular inhibitor $[22,23]$. Following an increase of intracellular calcium concentration, calpastatin was released from its association with calpain, allowing calpain activation [24, 25].

Calpains have been shown to be important mediators of both necrotic and PCD following excitotoxicity [26-28]. They are implicated in the cleavage of pro-apoptotic and anti-apoptotic proteins (p53, Bcl-2, Bax), depending on the nature of stimuli and cell type $[29,30]$. Therefore, the influences of calpains on caspases have been widely shown. Calpains exert a direct proteolysis of caspase- 3 and - 12 , generating several active fragments, while they exert an inhibitory function on the caspase-7, -8 and -9 [31,32]. Calpains could also be involved in necrotic death [33]. They might contribute to the intracellular $\mathrm{Ca}^{2+}$ overloading by cleaving the $\mathrm{Na}^{+} / \mathrm{Ca}^{2+}$ exchanger in the plasma membrane and activating cathepsins consequently to their action on lysosomal membrane permeability [34-36].

PCD is an essential process required for tissue remodelling during embryonic development; necrosis contributes to eliminate unwanted cells during embryogenesis [37, 38] like PCD [42]. Amphibians and more particularly Xenopus laevis are commonly used to understand the importance of PCD throughout development [39-42].

The aim of the present work was to determine the role of calpains in the regulation of PCD observed after Glu or KA applications. Several Xenopus laevis tadpoles were exposed to different concentrations of molecules.

\section{Material and methods}

Animals. Sexually mature Xenopus laevis frogs were obtained from the CNRS breeding facility (UPRES A6026, Université de Rennes I, France). Animals were bred in aquaria, with $40 \mathrm{~L}$ of dechlorinated tap water, changed every week. The room temperature was $22^{\circ} \mathrm{C} \pm 1^{\circ} \mathrm{C}$ under a 12:12 h light:dark photoperiod. Frogs were fed twice a week with trout feed chopped pellets. Animal manipulation was performed in accordance with the French legislation concerning animal welfare.

Spawning of female $X$. laevis was induced by injecting 750 IU of human chorionic gonadotropin (HCG, Organon, Oss, Netherlands), into the dorsal lymph sac 10-12 h before egg collection. Eggs were fertilised in vitro with the minced testis of one male. Embryos were fed twice a day with watercress soup and maintained until stage 48 . Development stages of Xenopus laevis were determined according to Nieuwkoop and Faber normal table [43]. Eight tadpoles were used for the present study.

Particularly investigated organs were skin and gills that were on direct contact with drugs. Several effects of drugs have been also totally or partially studied on intestine, dorsal muscle, heart and brain in order to show systemic consequences of toxicity.

Toxicity tests. All procedures were conducted under protocols approved by the Ethics Committee for animal research of France. Tests were conducted in 6-well culture plates, each plate containing 4 embryos. Tadpoles were exposed during 3 hours, at $23^{\circ} \mathrm{C}$, to serial dilutions in mineral water (Evian) of two molecules: Glu (30 mM, $60 \mathrm{mM}, 120 \mathrm{mM})$ or KA (0.015 mM, $0.15 \mathrm{mM}, 0.75 \mathrm{mM})$. A control group was maintained in pure Evian water. After treatment, all animals were immersed in mineral water for 24 hours, during which time Glu or KA can diffuse throughout the organs. Then, they were anaesthetised with MS222 (Sigma Aldrich, St Louis, MO, USA) and fixed in cold paraformaldehyde (4\%). Tadpoles were then totally embedded in paraffin and cut in transversal sections (5 or $7 \mu \mathrm{m})$. Two independent experiments were carried out.

Calpain detection. An indirect immunofluorescence method was used to determine the localisation of calpains in tadpoles. The slides were deparaffinised, rehydrated in PBS (0.1 M, pH 7.4), incubated in 1\% BSA for $15 \mathrm{~min}$ and stained for 1 hour with calpain antibodies. The antibodies used to highlight $\mu$ - and m-calpains were directed against human isoforms (mouse monoclonal anti-calpain 1 large subunit MAB3082, at 1:50 dilution, rabbit polyclonal anti-calpain 2 large subunit AB1625, at 1:25 dilution (Chemicon-Millipore, Billerica, MA, USA). Specific recognition of antibodies directed against human calpains for the $X$. laevis enzymes was previously verified 
[44]. After washing three times in PBS, the sections were incubated for 1 hour in room temperature with Alexa 488-conjugated anti-mouse IgG (1:100, Invitrogen-Life Technologies, Carlsbad, CA, USA) or $\mathrm{Cy}^{\mathrm{T}} 3$-labelled anti-rabbit IgG (1:100, Chemicon). Negative control by omission of primary antibody was carried out. Slides were observed with a Nikon Eclipse E400 microscope (Nikon, Tokyo, Japan), equipped with epifluorescence optics. The average fluorescence per pixel of each organ was calculated (Nis element Br, Nikon).

PCD visualisation. The Apostain assay (Eurobio-AbCys, Courtaboeuf, France) was used to stain apoptotic cells on animal sections [45]. Staining with the Apostain kit was performed following the manufacturer's instructions. After deparaffinisation and rehydration, slides were treated with a solution of proteinase $\mathrm{K}(20 \mu \mathrm{g} / \mathrm{mL})$ and saponine $(0.2 \mathrm{mg} / \mathrm{mL})$ for $20 \mathrm{~min}$ at room temperature and heated in formamide $\left(58^{\circ} \mathrm{C}\right)$ for $20 \mathrm{~min}$. After heating, they were transferred into ice-cold PBS, treated with $3 \% \mathrm{H}_{2} \mathrm{O}_{2}$ for 5 min, blocked in $3 \%$ non-fat dry milk, then stained with monoclonal antibody Apostain $(1 \mathrm{mg} / \mathrm{mL}$ in PBS, Eurobio-AbCys, Courtaboeuf, France) and peroxidase-conjugated anti-mouse IgM (1:500 in PBS, Millipore), each treatment for $30 \mathrm{~min}$ at room temperature. Diaminobenzidine (DAB) (Roche Diagnostics, Basel, Switzerland) was used as a chromogen and haematoxylin QS (Vector Laboratories, Burlingame, CA, USA) as a counterstain. The number of Apostain-positive cells per square micrometre of organ section was estimated by light microscopy. The Nis element BR software was used.

As a second method, activated caspase 3 was visualised on several sections using an immunohistochemical method. After deparaffinisation and rehydration, slides were incubated with proteinase $\mathrm{K}(20 \mu \mathrm{g} / \mathrm{mL})$ and saponine $(0.2 \mathrm{mg} /$ $\mathrm{mL})$. After quenching of endogenous peroxidase with $3 \%$ $\mathrm{H}_{2} \mathrm{O}_{2}$ for $5 \mathrm{~min}$, the sections were incubated with rabbit polyclonal antibody to cleave caspase 3 (1:50 dilution, Epitomics, Burlingame, CA, USA) for $60 \mathrm{~min}$ at room temperature. Immunodetection was performed using biotinylated anti-rabbit IgG and peroxydase-conjugated streptavidin (kit Vectastain Elite ABC Universal, Vector Laboratories) with $\mathrm{DAB}$ as the substrate. Slides were counterstained for $1 \mathrm{~min}$ with haematoxylin QS (1:4 dilution). For each experiment, control specimens were obtained by omitting incubation with the specific antibodies.

Statistical analysis. All values were expressed as mean \pm S.E.M. Data were normally distributed and values obtained were analysed by one-way analysis of variance (ANOVA). A post-hoc analysis was performed using Dunett's test for multiple comparisons. Differences between experimental and control samples were considered significant at $P<0.05$.

\section{Results}

\section{Effects of Glutamate or kainate treatment on apoptosis}

Preliminary experiments were carried out in order to determine the acute lethal toxicity of tested substances. After the toxic exposure, Xenopus laevis tadpoles (stage 48) were checked for mortality or morphological abnormalities; histological observations of organs were realised according to the atlas of Xenopus development [46]. Unlike the highest doses tested, no mortality was observed with exposure in Glu up to $120 \mathrm{mM}$, or in KA up to $0.75 \mathrm{mM}$. Several histological visualisation of PCDs and detection of calpain 1 or calpain 2 (immunofluorescence staining) are shown in Figure 1.

In external organs (skin and gills), a three-hours exposure to 30-120 mM Glu resulted in a concentration-dependent increase of PCD compared to controls (Figures 2, 3). In internal organs (brain, heart, intestine and muscle), the effect was not so progressive and a dramatic increase in apoptotic activity after exposure with $120 \mathrm{mM}$ Glu was observed (Figures 4-7). The strongest response occurred in the skin (Figure 2) and secondarily in the gills (Figure 3 ) and brain (Figure 4). The number of Apostain-stained cells reached 4730 cells $/ \mathrm{mm}^{2}$ in the skin, 1886 cells $/ \mathrm{mm}^{2}$ in the gills and 1753 cells $/ \mathrm{mm}^{2}$ in the brain, compared with 173 cells $/ \mathrm{mm}^{2}, 200$ cells $/ \mathrm{mm}^{2}$ and 17 cells $/ \mathrm{mm}^{2}$ respectively in control treatments. In the other internal organs, number of apoptotic cells was comprised between 200 and 600 (Figures 5-7). Several organs showed also apoptotic response when the tadpoles were exposed to $60 \mathrm{mM}$ Glu (Figures 2, 3, 5-7).

When tadpoles were exposed to $0.015-0.75 \mathrm{mM}$ KA, PCDs were observed in all the tissues (skin and gills for external organs, intestine and muscle for internal ones) whatever the concentration applied (Figures 2-7). The most significant effect was detected when tadpoles were exposed to $0.15 \mathrm{mM}$ KA. Like with Glu exposure, the different organs did not react on the same way to the treatment: the number of Apostain-stained cells was 34 times larger than the control in the skin (Figure 2), 9 times in the gills (Figure 3), 18 times in the intestine (Figure 6), 69 times in the dorsal muscle (Figure 7). The largest number of apoptotic cells was noticed in the skin and the gills (5757 cells/ $/ \mathrm{mm}^{2}$ and 1529 cells $/ \mathrm{mm}^{2}$ respectively) at $0.15 \mathrm{mM} \mathrm{KA}$ (Figures 2, 3). It was only comprised between 100 and 200 in intestine and muscle respectively (Figures 6, 7).

\section{Excitotoxicity and calpain immunoreactivity}

In order to determine the basic level in the organs studied, calpain immunoreactivity was established 

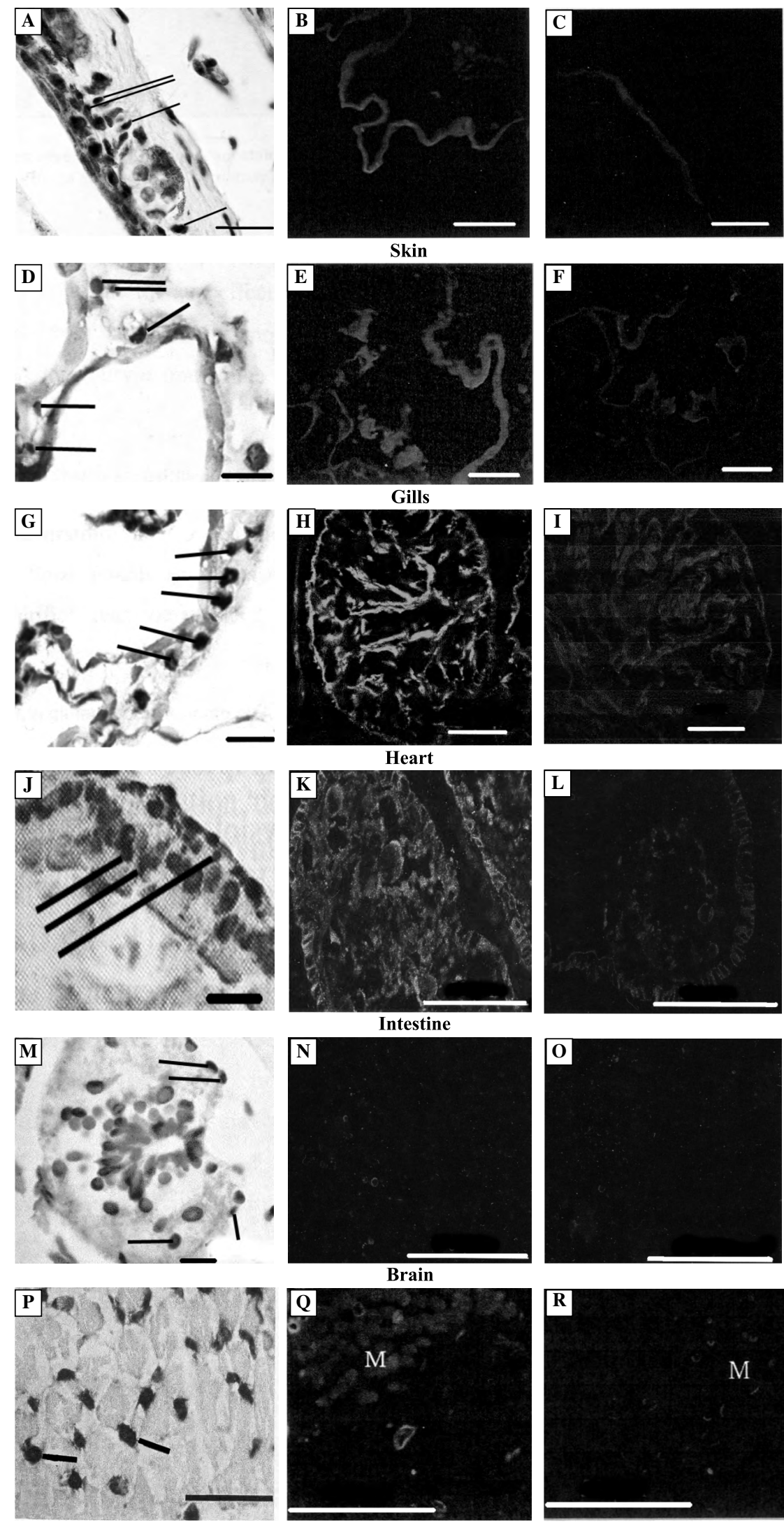

Dorsal muscle
Figure 1. Visualisation of apoptotic cells in gills and presence of calpain1 or calpain 2 on paraffin sections of Xenopus laevis tadpole (stage 48). A. visualisation of apoptotic cells (lines) on skin with Apostain method without any treatment, bar $=20$ $\mu \mathrm{m}$; B. visualisation of calpain 1 by immunofluorescence on skin after treatment with $60 \mathrm{mM} \mathrm{Glu}$, bar = $50 \mu \mathrm{m}$; C. control; visualisation of calpain 1 by immunofluorescence on skin, without any treatment, bar $=50$ $\mu \mathrm{m} ; \mathbf{D}$. visualisation of apoptotic cells (lines) on gills with Apostain method, bar $=20 \mu \mathrm{m}$; E. visualisation of calpain 2 by immunofluorescence on gills after treatment with $60 \mathrm{mM}$ Glu, bar $=50 \mu \mathrm{m} ; \mathbf{F}$. control; visualisation of calpain 1 by immunofluorescence on gill, without any treatment, bar = $50 \mu \mathrm{m}$; G. visualisation of apoptotic cells (lines) on gills with an anti-active caspase 3 antibody, bar $=20$ $\mu \mathrm{M}$; H. visualisation of calpain 1 by immunofluorescence on heart after treatment with $60 \mathrm{mM}$ Glu, bar = $50 \mu \mathrm{m}$; I. control; visualisation of calpain 1 by immunofluorescence on heart, without any treatment bar $=50 \mu \mathrm{m} ; \mathbf{J}$. visualisation of apoptotic cells (lines) on intestine with Apostain method, bar $=20$ $\mu \mathrm{m}$; K. visualisation of calpain 1 by immunofluorescence on intestine, after treatment with $30 \mathrm{mM}$ Glu bar $=50 \mu \mathrm{m}$; L. control; visualisation of calpain 1 by immunofluorescence on intestine, without any treatment, bar $=50 \mu \mathrm{m} ;$ M. visualisation of apoptotic cells (lines) on brain with Apostain method, bar $=20 \mu \mathrm{m}$; N. visualisation of calpain 1 by immunofluorescence on brain after treatment with $30 \mathrm{mM}$ Glu, bar $=50 \mu \mathrm{m}$; O. control; visualisation of calpain 1 by immunofluorescence on brain, without any treatment, bar $=50 \mu \mathrm{m}$; P. visualisation of apoptotic cells (arrows) on dorsal muscle without any treatment with Apostain method, bar $=20 \mu \mathrm{m}$; Q. visualisation of calpain 2 by immunofluorescence on dorsal muscle without any treatment, bar $=50 \mu \mathrm{m} ; \mathbf{R}$. control; visualisation of calpain 2 by immunofluorescence on dorsal muscle after omission of anti-calpain 2 , bar $=50 \mu \mathrm{m}$ on untreated animals (stage 48). Both calpain 1 and calpain 2 expressions were low, but ubiquitously expanded in Xenopus laevis tadpole organs (Figure 1). In many organs, the toxicological exposure led to 

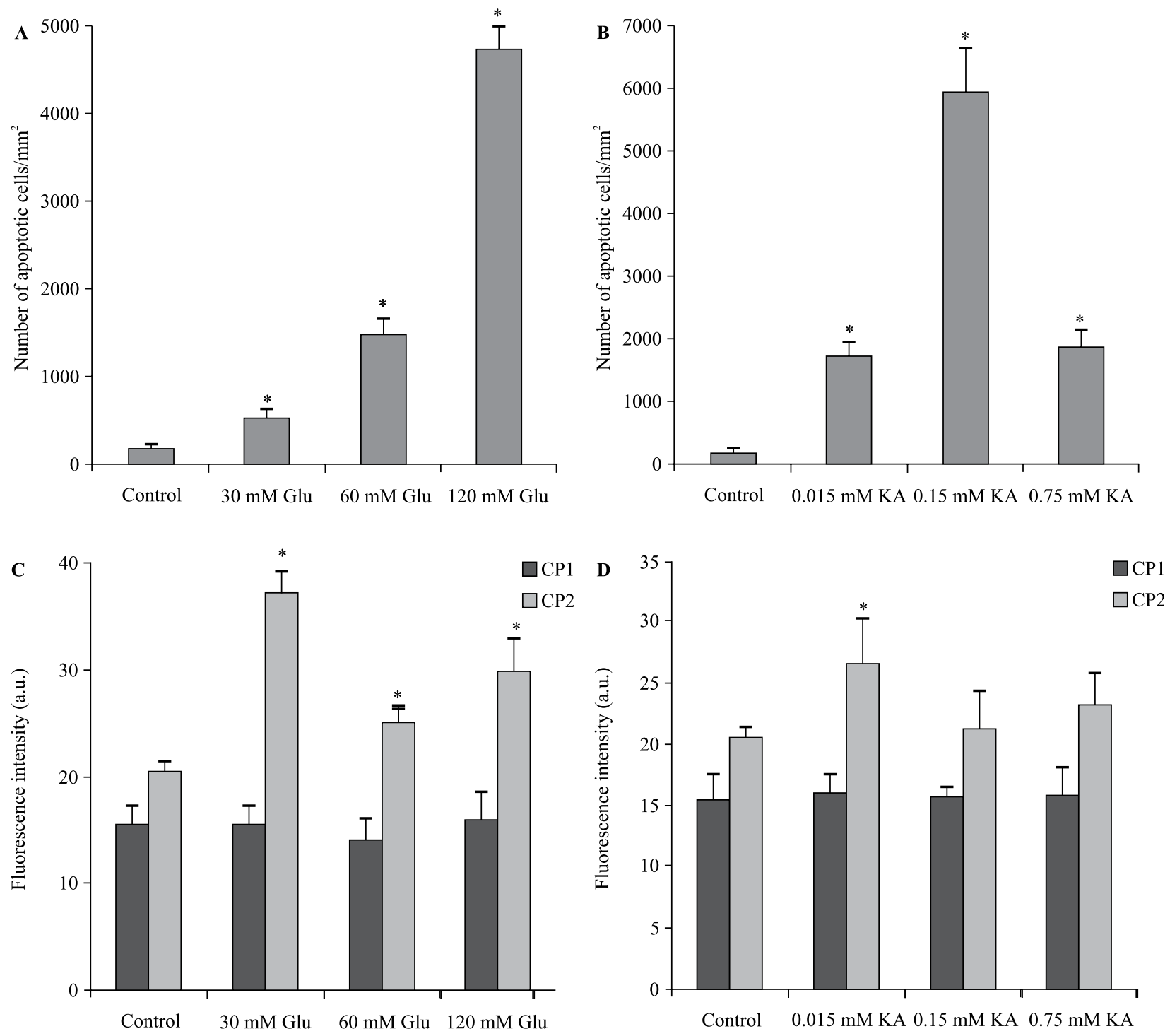

Figure 2. Effects on the skin of Xenopus laevis tadpole (stage 48) for $3 \mathrm{~h}$ exposure with different concentrations of Glu and KA. Number of apoptotic cells $/ \mathrm{mm}^{2}$ after treatment with different concentrations of Glu (A) or KA (B). Effect of Glu (C) or KA exposure (D) on ubiquitous calpain immunoreactivity. An indirect immunofluorescence method was used and the mean \pm S.E.M. fluorescence per pixel of each organ was determined (Nis element, Nikon). ANOVA followed by Dunett's test; $P<0.05,{ }^{*}$ significantly different with the control; $\mathrm{n}=8$

an increase of calpain immunoreactivity (Figures 2, $3,5,6)$. This increase was variable depending on to the treatment applied and the organ analysed. First, $30 \mathrm{mM}$ Glu was the most appropriate dose for a change on calpain immunoreactivity. Second, regardless the organ, the increase of calpain 2 immunoreactivity was always larger compared to calpain 1 one. In gills and skin, only the calpain 2 immunoreactivity was affected by the Glu treatment; no significant variation of calpain 1 immunoreactivity was observed (Figures 2,3). In heart and intestine, immunoreactivity of both calpain 1 and calpain 2 fluctuated with the glutamate exposure (Figures 5, 6).

No significant fluctuation of calpain 1 immunoreactivity was observed in tadpoles exposed to KA
$(0.015-0.75 \mathrm{mM})$. The variations of calpain $2 \mathrm{im}-$ munoreactivity were important when tadpoles were exposed to $0.015 \mathrm{mM}$ (Figures 2-7).

\section{Discussion}

Previous studies showed that physiological PCD was observable at the onset of gastrulation (stage 10.5) in Xenopus laevis development [39, 42, 43].

Throughout the entire development of Xenopus laevis, several waves of PCD have been visualised. A first one was observed at the onset of gastrulation, and depended on the maternal genes expressed at mid blastula transition (MBT). This first wave seemed to be related to the elimination of abnormal cells [42]. 

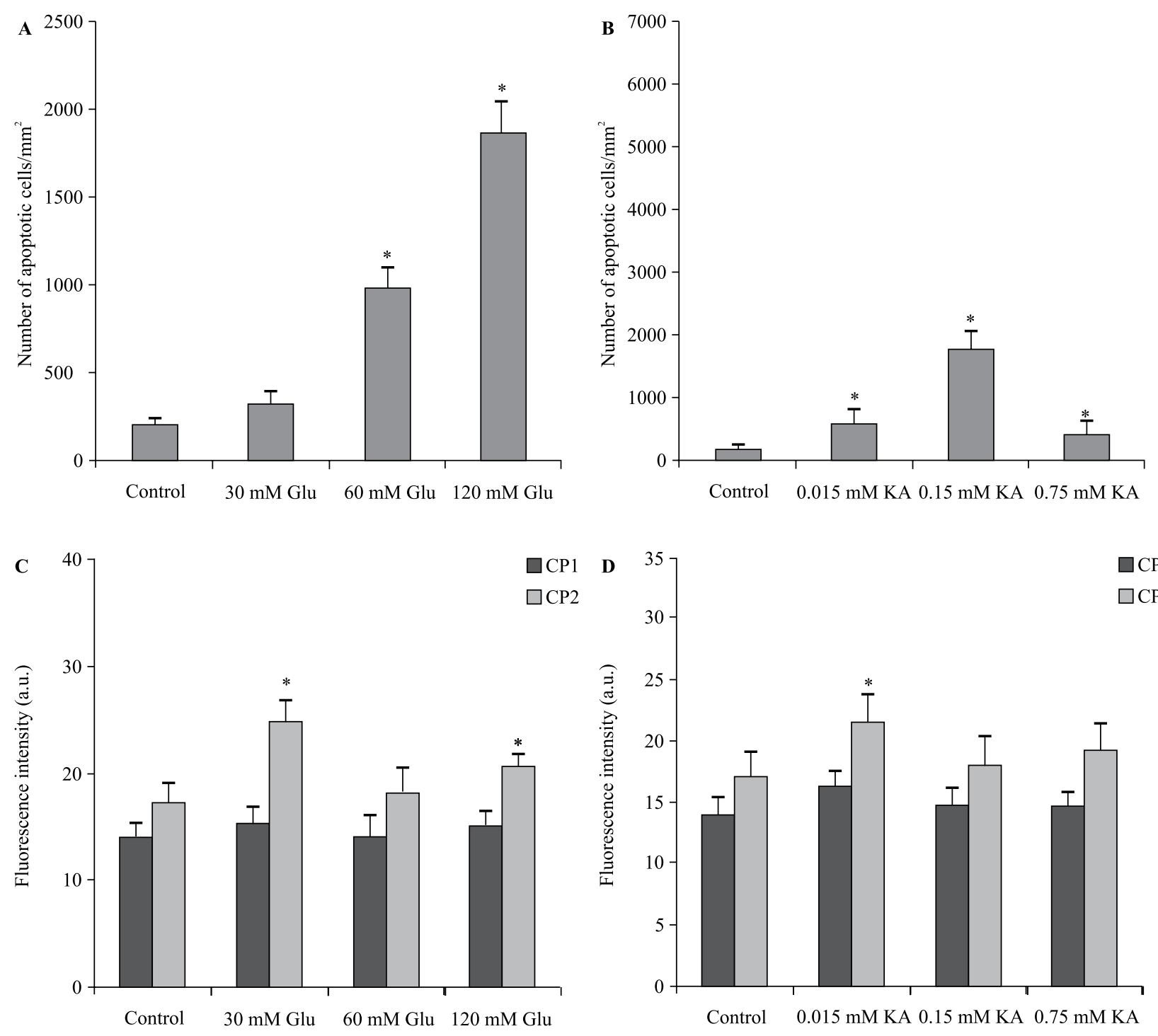

Figure 3. Effects on the gill of Xenopus laevis tadpole (stage 48) of $3 \mathrm{~h}$ exposure with different concentrations of Glu and KA. Number of apoptotic cells $/ \mathrm{mm}^{2}$ after treatment with different concentrations of Glu (A) or KA (B). Effect of Glu (C) or KA exposure (D) on ubiquitous calpain immunoreactivity. An indirect immunofluorescence method was used and the mean \pm S.E.M. fluorescence per pixel of each organ was determined (Nis element, Nikon). ANOVA followed by Dunett's test; $P<0.05$, significantly different with the control; $\mathrm{n}=8$

At gastrulation, a second wave of apoptotic cells was visualised in Xenopus laevis [39]. The first apoptotic cells of this wave were mainly observed around the blastopore. At the end of gastrulation, they were observed on the back of the embryo, underlining the future neural plate, and continued throughout neurulation. These cells would correspond to the differentiation of neural plate [39, 42]. Some comparable observations were also noted previously in the Japanese urodelans Cynops pyrhogaster [47]. This phenomenon involved the expression of several developmental genes such as Xotx2 or Xrx1 [48]. In X. laevis, Yeo and Gautier showed that PCD regulated the primary neural determination [49]. A third wave of apoptosis was then observed on late neurulation, when axons develop from maturating neurones. If the axons never attempt target cells, neurons become apoptotic. At this period, a combined action of several genes, some of them activator of PCD, the others inhibitor, acted on the construction of the future brain and spinal cord [42, 50-54]. During organ development (stages 35/36), several apoptotic cells were detected but PCDs were not numerous at the growth phase and especially at stage 48 . During the growth period (stage 48) no massive cell death occurred, although some apoptotic cells corresponding to a normal physiology were counted in most of the organs observed [41, 42]. So, this tadpole stage was 

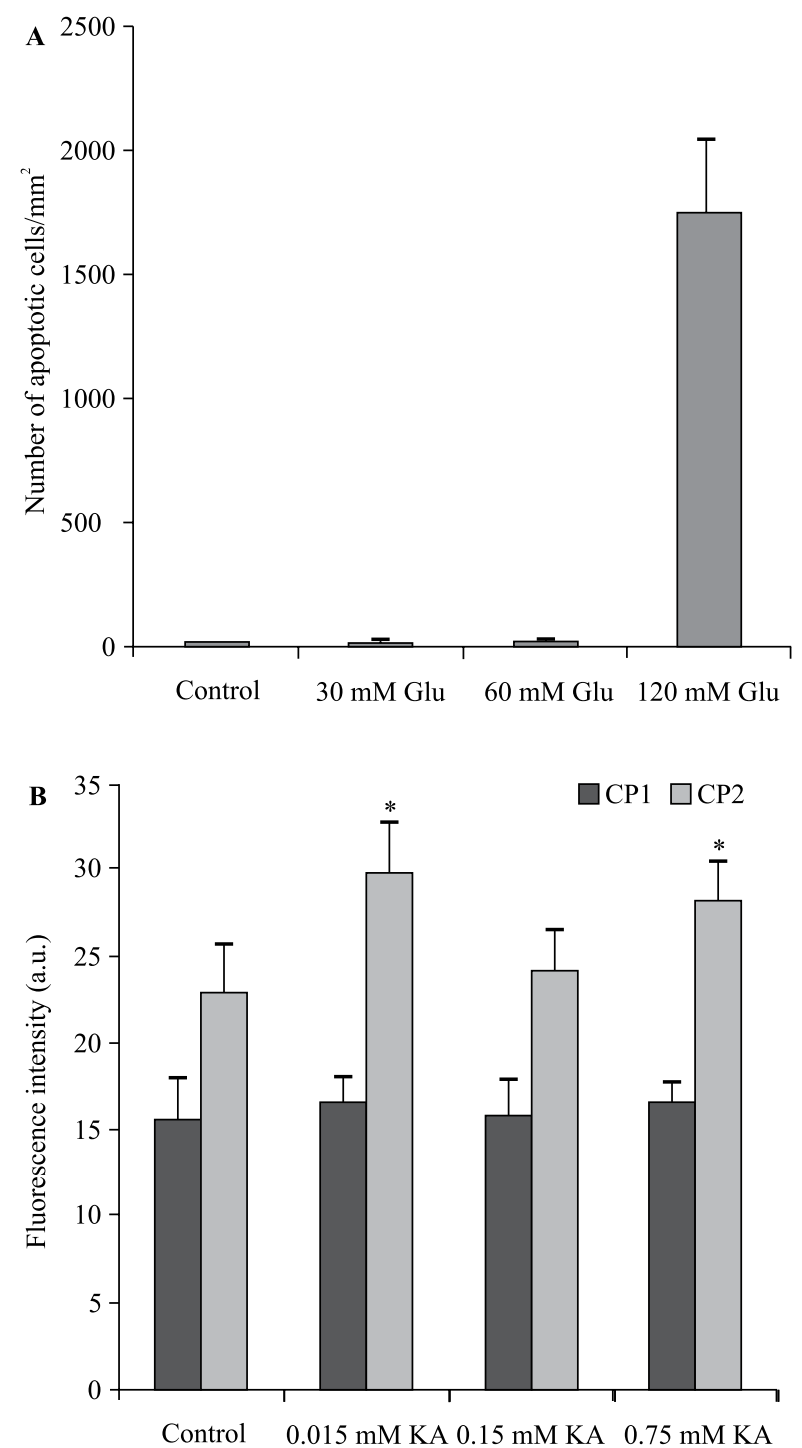

Figure 4. Effects on brain of Xenopus laevis tadpole (stage 48 ) of different exposure time and concentrations of Glu and KA. Number of apoptotic cells $/ \mathrm{mm}^{2}$ after treatment with different concentrations of Glu (A). Effect of KA exposure (B) on ubiquitous calpain immunoreactivity. An indirect immunofluorescence method was used and the mean \pm S.E.M. fluorescence per pixel of each organ was determined (Nis element, Nikon). ANOVA followed by Dunett's test; $P<0.05$, significantly different with the control; $\mathrm{n}=8$

suitable for study the toxicological-mediated apoptosis and the eventual involvement of calpain in this process. At metamorphosis, apoptosis were observed in developing and regressing organs more especially at stages $62 / 63$ [41, 55].

In the present study, we examined for the first time, as far as we know, the repercussion of calcium dysregulation induced by an overstimulation of iGluR, on PCD in an entire organism. The concentrations of Glu (30-120 mM) and KA (0.015-0.75 mM) used
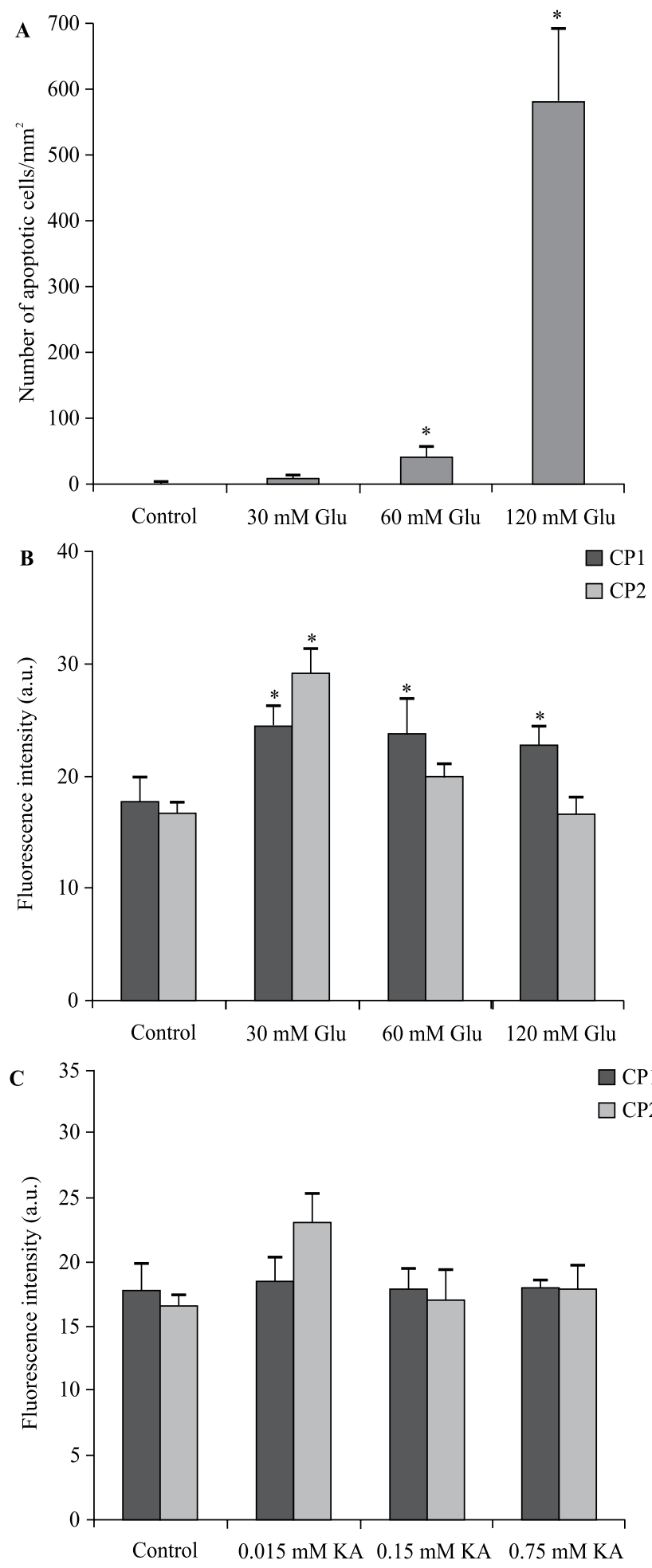

Figure 5. Effects on the heart of Xenopus laevis tadpole (stage 48 ) of different exposure time and concentrations of Glu and KA. Number of apoptotic cells $/ \mathrm{mm}^{2}$ after treatment with different concentrations of Glu (A). Effect of Glu (B) or KA exposure (C) on ubiquitous calpain immunoreactivity. An indirect immunofluorescence method was used and the mean \pm S.E.M. fluorescence per pixel of each organ was determined (Nis element, Nikon). ANOVA followed by Dunett's test; $P<0.05$, ${ }^{*}$ significantly different with the control; $\mathrm{n}=8$ 

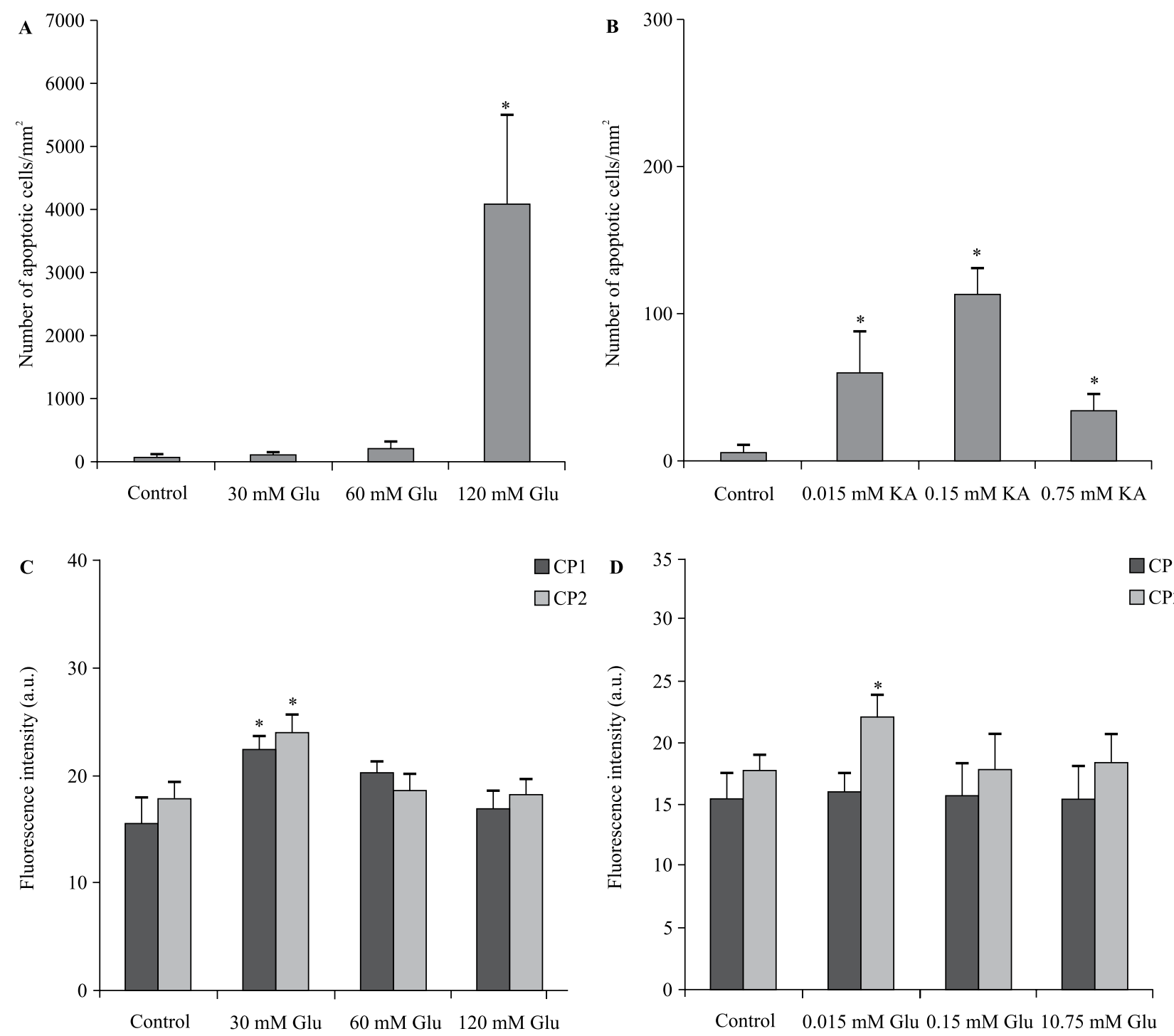

Figure 6. Effects on the intestine of Xenopus laevis tadpole (stage 48) of different exposure time and concentrations of Glu and KA. Number of apoptotic cells $/ \mathrm{mm}^{2}$ after treatment with different concentrations of Glu (A) or KA (B). Effect of Glu (C) or KA exposure (D) on ubiquitous calpain immunoreactivity. An indirect immunofluorescence method was used and the mean \pm S.E.M. fluorescence per pixel of each organ was determined (Nis element, Nikon). ANOVA followed by Dunett's test; $P<0.05$, significantly different with the control; $\mathrm{n}=8$

in this work were adapted to analyse the toxicity of the molecules in tadpole organism because no lethal effect was induced. This toxicity involved GluRs. Different studies showed that the presence of GluRs was not restricted to the nervous system. These receptors could be found in peripheral tissues and they were particularly described in Xenopus laevis [6, 56, 57]. The iGluRs were precociously expressed during embryogenesis and they appeared to become functional before the growth period in Xenopus laevis [58-60]. So drugs such as Glu or KA can act on different tissues inducing toxicological effects.

Xenopus laevis tadpoles were incubated during 3 hours with Glu (30-120 mM) or KA (0.015-0.75
$\mathrm{mM}$ ) and euthanisied $24 \mathrm{~h}$ latter. We observed PCDs triggered with Glu treatments and so, it was possible to establish a dose-response relationship. The number of apoptotic cells increased substantially for $60 \mathrm{mM}$ Glu and considerably for $120 \mathrm{mM}$ Glu. Responses to the administration of Glu are comparable from an organ to another, excepted for brain in which a lot of apoptotic cells were observed after application of an excess of Glu only. In the newborn rat retina also, an excess of Glu provokes an excess of apoptotic cells [61]. It is also possible that the different responses to Glu can be linked to the type of receptor activated or to the quantity of expressed glutamate receptors on the tissues. Experiments after KA exposure indicated 

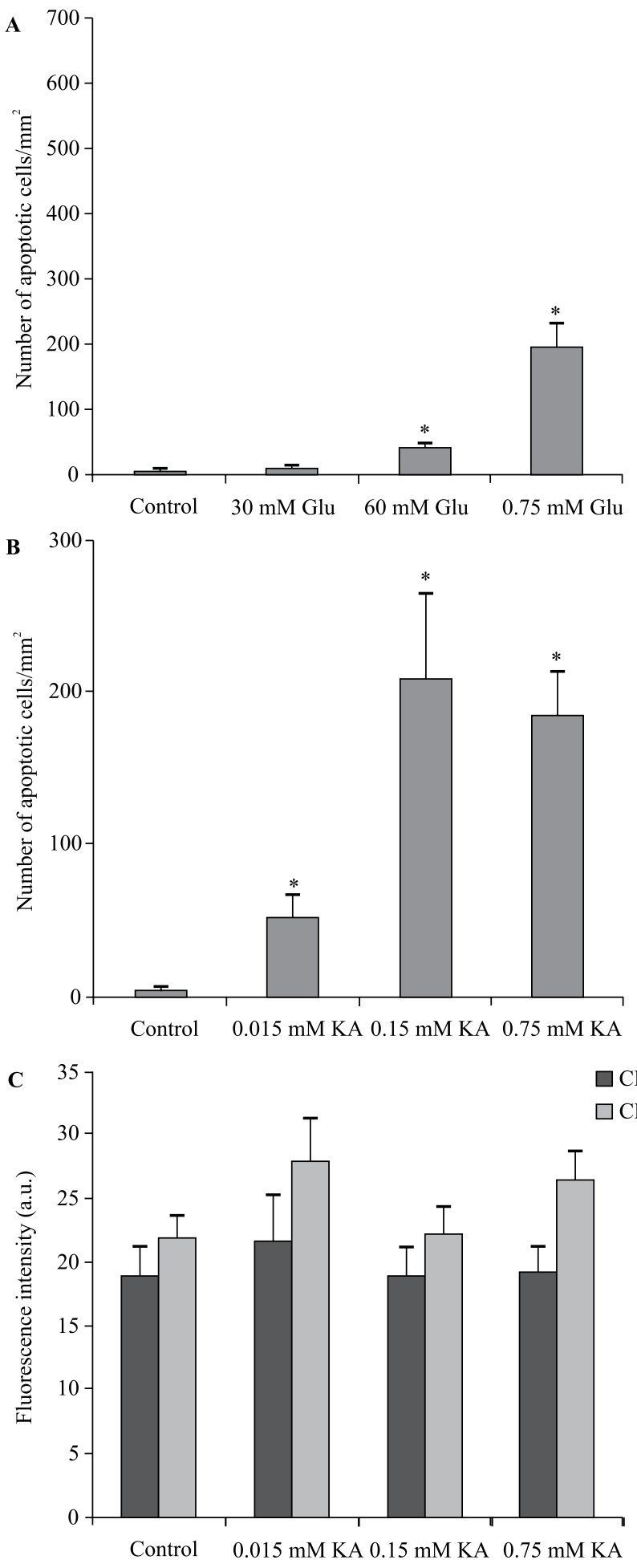

Figure 7. Effects on the dorsal muscle of Xenopus laevis tadpole (stage 48) of different exposure time and concentrations of Glu and KA. Number of apoptotic cells $/ \mathrm{mm}^{2}$ after treatment with different concentrations of Glu (A) or KA (B). Effect of KA exposure (C) on ubiquitous calpain immunoreactivity. An indirect immunofluorescence method was used and the mean \pm S.E.M. fluorescence per pixel of each organ was determined (Nis element, Nikon). ANOVA followed by Dunett's test; $P<0.05$, *significantly different with the control; $\mathrm{n}=8$ that apoptosis was induced with all doses tested and reached a peak with $0.15 \mathrm{mM} \mathrm{KA}$ in the majority of the organs examined, brain and heart excluded. The organs in direct contact with the molecules tested (i.e. skin and gills) appeared to be the most affected by Glu or KA treatment. These data confirmed that Glu and its analogues excessively stimulated the iGluRs. The excessive Glu or KA triggering massive calcium influx caused a cascade of biochemical processes which induced PCD.

Among these series of events, the activation of cysteine proteases appeared to be a key-step in the establishment of cell death. Among these proteases, calpains participated in both necrotic and apoptotic cell death, whereas caspases were especially activated only in apoptotic process [26, $33,62]$. Previous studies demonstrated that organs exposed to Glu or KA could undergo apoptosis or necrosis depending on intensity of exposure [63]. The increase of ubiquitous calpain was characterised in order to understand the role played by calpain in PCD accompanying the toxic effects of drugs. Previous studies showed that calpain 1 and calpain 2 were ubiquitously expressed from the first stages in X. laevis [44]. The results reported here show that $30 \mathrm{mM}$ Glu generated a large increase of the calpain immunoreactivity, but this peak did not match up with the peak of apoptosis (120 mM Glu). The progress of the calpain 2 immunoreactivity was inversely proportional to apoptosis' one, except in the skin and gills. The results obtained after KA exposure were comparable because calpain immunoreactivity was maximal with $0.015 \mathrm{mM} \mathrm{KA}$ and apoptotic cell death with $0.15 \mathrm{mM} \mathrm{KA}$. Therefore we observed that immunoreactivity of calpain 1 did not significantly fluctuate compared to that of calpain 2 . These results suggested firstly that calpains were involved in the response to poisoning by Glu (or its analogues), secondly that their immunoreactivity did not increase when apoptosis occurred, and finally that their implication in the toxic cell damage differed according to the ubiquitous calpain considered.

Different studies focused on the physiological impact of calpain on the functions of ionotropic receptors in neurons, but no evidence occurred on GluR in peripheral tissues [28, 64-67]. In this study we have shown that calpains could be negative regulators of the cell death depending on the magnitude of the applied stimulus. Effectively, when tadpoles were exposed with $30 \mathrm{mM}$ Glu, the activated calpains, further to an input of $\mathrm{Ca}^{2+}$ through NMDAR, split the GluRs. This proteolysis allowed limitation of calcium entrance by the ion channels and then prevented cells from death. This possible regulating effect of the cal- 
pains was shown on different GluRs on neuronal level. It has been shown that the NR2 subunit subtypes, present in NMDARs and containing the Glu-binding site, were cleaved by calpains at their C-terminal regions [64]. In situ experiments with transfected cells have shown that calpains-generated $\mathrm{N}$-terminal fragment was further degraded by other proteolytic mechanisms that reduced the functional NMDARs and permitted a protective cell death mechanism during excitotoxicity $[14,68]$. The post-translational phosphorylation of NR2 subunits protects against calpains-mediated truncation of these NR2 subunits [69]. When the tadpoles were in contact with $120 \mathrm{mM}$ Glu, Apoptosis was very important and the activation of calpains was lower than after intoxication with $30 \mathrm{mM}$ Glu. In a recent work the activation of calpain (the name of calpain is not specified in the paper), has been observed after the administration of Glu into the rat striatum [70]. An effect of this activation was the cleavage of $\alpha$-spectrin, a cytoskeletal protein involved in PCD. This response involved both NMDARs and non-NMDARs. In Xenopus laevis, it is also likely that AMPA receptors are involved in the activation of the ubiquitous calpain 2. Indeed, previous studies have shown that these receptors are present and functional in tadpoles [58]. PCDs were finally mainly induced by the activation of NMDAR but also by other factors independent of ionotropic receptors. In Amphibians, AMPA/Kainate receptors have been visualised in several species. In Xenopus laevis, GluR2 and GluR3, subunits of these receptors have been detected by immunohistochemistry in several organs during embryonic development [71]. In Rana esculenta and Bufo bufo, the presence of AMPA/kainate receptors, which are ionotropic receptors permeable to calcium, has been demonstrated with a technique based on the accumulation of cobalt in cells after the activation of receptors [58]. These receptors are present on all the organs of tadpoles [56, 71].

When tadpoles were in contact with $0.015 \mathrm{mM}$ $\mathrm{KA}$, the $\mathrm{Ca}^{2+}$ influx might occur via several pathways, including NMDAR, several types of $\mathrm{Ca}^{2+}$ permeable non-NMDAR channels, or $\mathrm{Na}^{+} / \mathrm{Ca}^{2+}$ exchangers [63, $72,73]$. The modification of calcium homeostasis was sufficient to increase the quantity of immunoreactive calpain in most of cell types.

Consequently to the activation of calpains after intoxication with Glu $(30 \mathrm{mM})$ or KA $(0.015 \mathrm{mM})$, a negative feedback reducing the activity of nonNMDARs and protecting the cells from toxicity was observed. Effectively the non-NMDARs were also substrates of calpain and their cleavage lead to a significant reduction in the number of functional channels on cell membranes allowing protection [65].
It should be noted that the susceptibility of the nonNMDARs to calpain cleavage was dependent on the phosphorylation state of the subunits [66]. On the other hand, an exposition to $0.15 \mathrm{mM} \mathrm{KA}$ generated a high increase of apoptotic cell number compared with control cells, however without any increase of calpains' immunoreactivity. These results suggest therefore that the caspase pathway was preferred following an important intoxication by KA; calpains being not required for KA-mediated apoptosis. Finally, an exposition of tadpoles to $0.75 \mathrm{mM} \mathrm{KA}$ generated very likely PCD but mainly by necrosis, with calpains involvement. Calpain 2 is the main calpain involved in the Glu- or KA-induced cell death. Some of the organs did not react to intoxication by Glu or KA and they were not affected at the same degree by the same drugs. Moreover, it is likely that the number of GluRs on the surface of the organs was different [56].

In the present study we have set out to characterise the role of calpains in response to GluRs activation in different organs of $X$. laevis tadpoles. We have shown that the intoxication of tadpoles by non-lethal doses of Glu or KA caused some variations of the quantity of ubiquitous calpains, mainly of calpain 2 , and an increase of cell death. Calpains could be positive or negative regulators of the apoptosis, depending on the cleaved pro- or anti-apoptotic molecules. When the calpain-mediated protective mechanism is overridden by an excessive activation of pro-apoptotic molecules, the downstream cell death pathways will be triggered. So calpains and caspases are both activated during drug-induced apoptosis and calpains, along with caspases, may be involved in modulating cell death by acting selectively on cellular substrates. Calpains could also be a regulator of necrosis. By cleaving the glutamate receptors, the calpains appear to control the physiology and the functions of GluRs and consequently the toxicological effects of Glu or KA, provided the toxicology is not too high.

\section{References}

1. Sahai S. Glutamate in the mammalian CNS. Eur Arch Psychiatry Clin Neurosci. 1990;240:121-133.

2. Conn PJ. Physiological roles and therapeutic potential of metabotropic glutamate receptors. Ann N Y Acad Sci. 2003;1003:12-21.

3. Niswender CM, Conn PJ. Metabotropic glutamate receptors: physiology, pharmacology, and disease. Annu Rev Pharmacol Toxicol. 2010;50:295-322.

4. Traynelis SF, Wollmuth LP, McBain CJ et al. Glutamate receptor ion channels: structure, regulation, and function. Pharmacol Rev. 2010;62:405-496.

5. Dingledine R, Borges K, Bowie D et al. The Glutamate Receptor Ion Channels. Pharmacology. 1999;86:1-17. 
6. Gill SS, Pulido OM. Glutamate receptors in peripheral tissues: current knowledge, future research, and implications for toxicology. Toxicol Pathol. 2001;29:208-223.

7. Roberts PJ, Davies SW. Excitatory receptors and their role in excitotoxicity. Biochem Soc Trans. 1987;15:218-219.

8. Lau A, Tymianski M. Glutamate receptors, neurotoxicity and neurodegeneration. Pflugers Arch. 2010;460:525-542.

9. Rothman SM, Olney JW. Excitotoxicity and the NMDA receptor — still lethal after eight years. Trends Neurosci. 1995;18:57-58.

10. Petrović M, Horák M, Sedlácek M et al. Physiology and pathology of NMDA receptors. Prague Med Rep. 2005;106:113-136.

11. Verkhratsky A. Calcium and cell death. Subcell Biochem. 2007;45:465-480.

12. Vanderklish PW, Bahr BA. The pathogenic activation of calpain: a marker and mediator of cellular toxicity and disease states. Int J Exp Pathol. 2000;81:323-339.

13. Wu HY, Tomizawa K, Matsui H. Calpain-calcineurin signaling in the pathogenesis of calcium-dependent disorder. Acta Med Okayama. 2007;61:123-137.

14. Doshi S, Lynch D. Calpain and the glutamatergic synapse. Frontiers in Biosciences. 2009;1:466-476.

15. Saido TC, Sorimachi H, Suzuki K. Calpain: new perspectives in molecular diversity and physiological-pathological involvement. FASEB J. 1994;8:814-822.

16. Goll DE, Thompson VF, Li H et al. The calpain system. Physiol Rev. 2003;3:731-801.

17. Suzuki K, Hata S, Kawabata Y, Sorimachi H. Structure, activation and biology of calpain. Diabetes. 2004;53(Suppl. 1):S12-S18.

18. Suzuki K, Sorimachi H. A novel aspect of calpain activation. FEBS Letters. 1998;433:1-4.

19. Perrin BJ, Huttenlocher A. Calpain. Int J Biochem Cell Biol. 2002;34:722-725.

20. Sorimachi H, Ono Y. Regulation and physiological roles of the calpain system in muscular disorders. Cardiovasc Res. 2012;96:11-22.

21. Campbell RL, Davies PL. Structure-function relationships in calpains. Biochem J. 2012;447:335-351.

22. Melloni E, Averna M, Stifanese R et al. Association of calpastatin with inactive calpain: a novel mechanism to control the activation of the protease? J Biol Chem. 2006;281:24945-24954.

23. Wendt A, Thompson VF, Goll DE. Interaction of calpastatin with calpain: a review. Biol Chem. 2004;385:465-472.

24. Suzuki K, Imajoh S, Emori Y et al. Calcium-activated neutral protease and its endogenous inhibitor. Activation at the cell membrane and biological function. FEBS Letters. 1987;220:271-277.

25. Murachi T. Intracellular regulatory system involving calpain and calpastatin. Biochem Int. 1989;8:263-294.

26. Harwood SM, Yaqoob MM, Allen DA. Caspase and calpain function in cell death: bridging the gap between apoptosis and necrosis. Ann Clin Biochem. 2005;42:415-431.

27. Mansouri B, Henne WM, Oomman SK et al. Involvement of calpain in AMPA-induced toxicity to rat cerebellar Purkinje neurons. Eur J Pharmacol. 2007;557:106-114.

28. Sánchez-Gómez MV, Alberdi E, Pérez-Navarro E et al. Bax and calpain mediate excitotoxic oligodendrocyte death induced by activation of both AMPA and kainate receptors. J Neurosci. 2011;31:2996-3006.

29. Wood DE, Thomas A, Devi LA et al. Bax cleavage is mediated by calpain during drug-induced apoptosis. Oncogene. 1998;17:1069-1078.

30. Tan Y, Wu C, De Veyra T et al. Ubiquitous calpains promote both apoptosis and survival signals in response to different cell death stimuli. J Biol Chem. 2006;281:17689-17698.
31. Chua BT, Guo K, Li P. Direct cleavage by the calcium-activated protease calpain can lead to inactivation of caspases. J Biol Chem. 2000;275:5131-5135.

32. Łopatniuk P, Witkowski JM. Conventional calpains and programmed cell death. Acta Biochim Pol. 2011;58:287-296.

33. Wang KK. Calpain and caspase: can you tell the difference? Trends Neurosci. 2000;23:20-26.

34. Yamashima T. Ca2+-dependent proteases in ischemic neuronal death: a conserved 'calpain-cathepsin cascade' from nematodes to primates. Cell Calcium. 2004;36:285-293.

35. Bano D, Young KW, Guerin CJ et al. Cleavage of the plasma membrane $\mathrm{Na}+/ \mathrm{Ca} 2+$ exchanger in excitotoxicity. Cell. 2005;120:275-285.

36. Zong WX, Thompson CB. Necrotic death as a cell fate. Genes Dev. 2006;20:1-15.

37. Jacobson MD, Weil M, Raff MC. Programmed cell death in animal development. Cell. 1997;88:347-354.

38. Lindsten T, Ross AJ, King A et al. The combined functions of proapoptotic Bcl-2 family members bak and bax are essential for normal development of multiple tissues. Mol Cell. 2000;6:1389-1399.

39. Hensey C, Gautier J. Programmed cell death during Xenopus development: a spatio-temporal analysis. Dev Biol. 1998;203:36-48.

40. Schreiber AM, Cai L, Brown D. Remodeling of the intestine during metamorphosis of Xenopus laevis. PNAS. 2002;99:12230-12235.

41. Estabel J, Mercer A, König N, Exbrayat JM. Programmed cell death in Xenopus laevis spinal cord, tail and other tissues, prior to, and during, metamorphosis. Life Sci. 2003;73:3297-3306.

42. Exbrayat JM, Moudilou EA, Abrouk L, Brun C. Apoptosis in amphibian development. Adv Biosci Biotechnol. 2012;3:669-678.

43. Nieuwkoop PD, Faber J. Normal table of Xenopus laevis (Daudin). Amsterdam: Eds North-Holland Publ Comp; 1967.

44. Moudilou EN, Mouterfi N, Exbrayat JM, Brun C. Calpains expression during Xenopus laevis development. Tissue Cell. 2010;42:275-281.

45. Frankfurt OS, Krishan A. Identification of apoptotic cells by formamide-induced DNA denaturation in condensed chromatin. J Histochem Cytochem. 2001;49:369-378.

46. Bernardini G, Prati M, Bonetti E, Scari G. Atlas of Xenopus development. Milano, Springer-Verlag 1999.

47. Imoh H. Cell death during normal gastrulation in the newt, Cynops pyrrhogaster. Cell Diff. 1986;19:35-42.

48. Andreazzoli M, Gestri G, Angeloni D et al. Role of Xrx1 in Xenopus eye and anterior brain development. Development. 1999;126:2451-2460.

49. Yeo W, Gautier J. A role for programmed cell death during early neurogenesis in Xenopus. Dev. Biol. 2003;260:31-45.

50. Tribulo C, Aybar M, Sanchez SS et al. A balance between the anti-apoptotic activity of Slug and the apoptotic activity of msx1 is required for the proper development of the neural crest. Dev Biol. 2004;275:325-342.

51. Aybar MJ, Nieto A, Mayor R. Snail precedes slug in the genetic cascade required for the specification and migration of the Xenopus neural crest. Development. 2003;30:483-494.

52. La Bonne C, Bronner-Fraser M. Snail related transcriptional repressors are required in Xenopus for both the induction of the neural crest and its subsequent migration. Dev Biol. 2000;221:195-205.

53. Mayor R, Guerrero N, Young RM et al. A novel function for the Xslug gene: Control of dorsal mesendoderm development by repressing BMP-4. Mech Dev. 2000;97:47-56.

54. Schneider M, Schambony A, Wedlich D. Prohibitin1 acts as a neural crest specifier in Xenopus development by 
repressing the transcription factor E2F1. Development. 2010;137:4073-4081.

55. Estabel J, König N, Shiokawa K, Exbrayat JM. Apoptosis in Xenopus genus. In: Scovassi I. (ed.). Apoptosis. Trivandrum, Research Signpost 2005:147-156.

56. Estabel J, Exbrayat JM. Localisation des récepteurs AMPA kaïnate dans les organes périphériques chez Xenopus laevis par immunohistochimie. Rev Fr Histotechnol. 2002;15:9-14.

57. Julio-Pieper M, Flor PJ, Dinan TG et al. Exciting times beyond the brain: metabotropic glutamate receptors in peripheral and non-neural tissues. Pharmacol Rev. 2011;63:35-58.

58. Estabel J, König N, Exbrayat JM. AMPA/kainate receptors permeable to divalent cations in amphibian central nervous system. Life Sci. 1999;64:607-616.

59. Issberner JP, Sillar KT. The contribution of the NMDA receptor glycine site to rhythm generation during fictive swimming in Xenopus laevis tadpoles. Eur J Neurosci. 2007;26:2556-2564.

60. Schmidt C, Klein C, Hollmann M. Xenopus laevis oocytes endogenously express all subunits of the ionotropic glutamate receptor family. J Mol Biol. 2009;390:182-195.

61. Dénes V, Lakk M, Czotter N et al. A precise temporal dissection of monosodium glutamate-induced apoptotic events in newborn rat retina in vivo. Neurochem Res. 2011;36:1464-1474.

62. Golstein P, Kroemer G. Cell death by necrosis: towards a molecular definition. Trends Biochem Sci. 2007;32:37-43.

63. Verdaguer E, Garcia-Jorda E, Jimenez A et al. Kainic acid-induced neuronal cell death in cerebellar granule cells is not prevented by caspase inhibitors. Br J Pharmacol. 2002;135:1297-1307.
64. Wu HY, Yuen EY, Lu YF et al. Regulation of N-methyl-D -aspartate receptors by calpain in cortical neurons. $J$ Biol Chem. 2005;280:21588-21593.

65. Yuen EY, Liu W, Yan Z. The phosphorylation state of GluR1 subunits determines the susceptibility of AMPA receptors to calpain cleavage. J Biol Chem. 2007;282:16434-16440.

66. Yuen EY, Gu Z, Yan Z. Calpain regulation of AMPA receptor channels in cortical pyramidal neurons. J Physiol. 2007;580:241-254.

67. Chen Z, Peppi M, Kujawa SG et al. Regulated expression of surface AMPA receptors reduces excitotoxicity in auditory neurons. J Neurophysiol. 2009;102:1152-1159.

68. Guttmann RP, Sokol S, Baker DL et al. Proteolysis of the $\mathrm{N}$-methyl-d-aspartate receptor by calpain in situ.J Pharmacol Exp Ther. 2002;302:1023-1030.

69. Bi R, Rong Y, Bernard A et al. Src-mediated tyrosine phosphorylation of NR2 subunits of N-methyl-D-aspartate receptors protects from calpain-mediated truncation of their C-terminal domains. J Biol Chem. 2000;275:26477-26483.

70. Del Rio P, Montiel T, Massieu L. Contribution of NMDA and non-NMDA receptors to in vivo glutamate-induced calpain activation in the rat striatum. Relation to neuronal damage. Neurochem Res. 2008;33:1475-1483.

71. Estabel J.Apoptoses physiologiques et apoptosis expérimentalement induites au cours du Développement de Xenopus laevis. PhD, EPHE:2004. Lyon.

72. Brorson JR, Manzolillo PA, Miller RJ. Ca2+ entry via AMPA/KA receptors and excitotoxicity in cultured cerebellar Purkinje cells. J Neurosci. 1994;14:187-197.

73. Burnashev N, Zhou Z, Neher E et al. Fractional calcium currents through recombinant GluR channels of the NMDA, AMPA and kainate receptor subtypes. J Physiol. 1995;485:403-418.

Submitted: 24 July, 2013

Accepted after reviews: 11 December, 2013 